\title{
CRIAÇÃO, TECNOLOGIA E LEGISLAÇÃO: O TRIPÉ DA CADEIA PRODUTIVA DO MERCADO MUSICAL NA ATUALIDADE
}

\section{ESTADO DA ARTE}

BARBOSA JUNIOR, Elenisio Rodrigues ${ }^{1}$, CORREA, Thiago Pessanha ${ }^{2}$

BARBOSA JUNIOR, Elenisio Rodrigues. CORREA, Thiago Pessanha. Criação, tecnologia e legislação: o tripé da cadeia produtiva do mercado musical na atualidade. Revista Científica Multidisciplinar Núcleo do Conhecimento. Ano 06, Ed. 06, Vol. 06, pp. 85-101. Junho de 2021. ISSN: 2448-0959, Link de acesso: https://www.nucleodoconhecimento.com.br/arte/cadeia-produtiva, DOI: 10.32749/nucleodoconhecimento.com.br/arte/cadeia-produtiva

\section{RESUMO}

Este artigo é resultado de uma análise histórica dos avanços do mercado musical até a atualidade e pretende ser uma contribuição para gerar reflexões sobre os processos de remuneração de autores, artistas, intérpretes, produtores fonográficos e demais atores da cena cultural. Para tanto, temos como base prática os três pilares da indústria fonográfica: Música, Tecnologia e Legislação, considerando esses três mecanismos como referência para a consolidação da indústria criativa cultural no Brasil. Do ponto de vista metodológico, descreveremos seis tópicos que abordarão: os direitos autorais, a transição do mercado musical, os impactos na produção, as formas de remuneração, a dinâmica do mercado musical, a legislação e os avanços tecnológicos e da produção musical na Internet. Embora as transformações recentes

\footnotetext{
${ }^{1}$ Especialização em Artes e Educação pela Faculdade Luso Capixaba e graduação em Bacharelado em Música com Habilitação em Piano pela Faculdade de Música do Espírito Santo "Maurício de Oliveira"

2Especialização em Artes e Educação pelo Instituto Superior de Educação de Afonso Cláudio e graduação em Licenciatura em Música e Técnico em Música Popular/Piano pela Faculdade de Música do Espírito Santo "Maurício de Oliveira"
}

RC: 88177

Disponível em: https://www.nucleodoconhecimento.com.br/arte/cadeia-produtiva 
tenham impacto direto na forma de produção e consumo da sociedade atual, o tema deste artigo é de suma relevância e visa elucidar o modus operandi da cadeia produtiva cultural da atualidade.

Palavras-chave: Música, Tecnologia e Comunicação, Direito Autoral, Cadeia Produtiva, Remuneração dos Artistas.

\section{INTRODUÇÃO}

Ainda na década de 1970, quando o Brasil vivia avanços consideráveis na indústria e em setores da economia, a relação entre artistas e editoras era amadora. Portanto, naquela época prevalecia a vontade das editoras, que estabelecia uma relação desdenhosa com a obra dos artistas. Martins Filho (1998, p.183), afirma que

Predominava até então uma relação paternalista entre editor e autor. Aquele agindo como um benfeitor, e este aceitando a publicação de seu livro como um favor, pois via seu ofício de escritor como uma missão, e não um meio de vida. Falar na venda de seu livro era quase uma heresia.

Dessa maneira, por não conhecerem os seus direitos, os artistas aceitaram que um terceiro - a editora - gerisse e publicasse as suas obras, pois acreditavam que 0 que deveria ser a sua atividade laboral era um chamado divino e não uma forma de sobrevivência. Nessa lógica, o trabalho de edição e divulgação de obras artísticas era visto como um ato de gentileza.

A ruptura dessa desinformação começa a acontecer quando os artistas passam a perceber que a relação mercadológica que se estabelece entre suas obras e a sociedade é uma questão de sobrevivência. Sendo assim, inicia-se uma nova etapa, onde artistas/autores começam a se posicionar como profissionais e passam a exigir contratos que legitimam seus direitos e garantam de forma mais eficaz seu trabalho. Esse conflito se devia fundamentalmente ao desconhecimento das leis existentes por parte dos artistas e por não haver legislação que regulamentasse e protegesse as obras intelectuais no Brasil.

$\mathrm{RC}: 88177$

Disponível em: https://www.nucleodoconhecimento.com.br/arte/cadeia-produtiva 
Se até hoje os direitos autorais relativos à publicação são quase totalmente desconhecidos, o que podemos falar de outros direitos como os de imagens, sons, programas, hardware e software e os conteúdos disponibilizados na Internet? Para melhor compreender esta questão, este artigo tem como objetivo analisar, com base na linha do tempo, a era analógica das obras intelectuais até a era atual, onde as tecnologias e as redes de informação digital impactam diretamente a produção artística.

\section{DIREITO AUTORAL NO BRASIL}

Os direitos autorais foram regulamentados no Brasil pela Lei 5.988, de 14 de dezembro de 1973. Posteriormente, essa Lei foi revogada pela Lei 9.610, de 19 de fevereiro de 1998, que atualizou e consolidou a lei dos direitos autorais, tomou outras providências e começou a vigorar cento e vinte dias após sua publicação.

Em suas Disposições Preliminares, a Lei regula os efeitos jurídicos sobre os negócios jurídicos relacionados aos direitos autorais, mais especificamente, aqueles relativos a autores, intérpretes, produtores fonográficos, etc.

Em seu artigo 5ำ, define publicação, transmissão ou difusão, retransmissão, distribuição, comunicação ao público, reprodução, contrafação, obra (em coautoria, anônima, pseudônimo, não publicada, póstuma, original, derivada, coletiva, audiovisual), fonograma, editor, produtor, radiodifusão, artistas intérpretes ou executantes e titular originário.

O artigo $6^{\circ}$ salienta que "não serão de domínio da União, dos Estados, do Distrito Federal ou dos Municípios as obras por eles simplesmente subvencionadas". Nesse sentido, o Estado não terá direito de propriedade sobre as obras pelo simples fato de subsidiá-las. Desse modo, o artigo $6^{\circ}$ definitivamente esclarece um problema que gerou muita discussão. Para um melhor entendimento, os principais aspectos da nova lei de direitos autorais serão definidos resumidamente a seguir.

$\mathrm{RC}: 88177$

Disponível em: https://www.nucleodoconhecimento.com.br/arte/cadeia-produtiva 
São obras intelectuais protegidas as criações do espírito, expressas por qualquer meio ou fixadas em qualquer suporte, tangível ou intangível, conhecido ou que se invente no futuro. Estão incluídos aqui textos de obras literárias, artísticas ou científicas; conferências, alocuções, sermões etc.; obras dramáticas e dramático-musicais; obras coreográficas cuja execução cênica se fixe por escrito ou por outra forma qualquer; obras audiovisuais, sonorizadas ou não, inclusive as cinematográficas; obras fotográficas; desenho, pintura, gravura, escultura, litografia, arte cinética; ilustrações e mapas; projetos, esboços e obras plásticas referentes à arquitetura, paisagismo, cenografia etc.; adaptações, traduções e outras informações de obras originais, apresentadas como criação intelectual nova; programas de computador; coletâneas, antologias, enciclopédias, dicionários, base de dados, que, por sua seleção, organização ou disposição de seu conteúdo, constituem uma criação intelectual. (MARTINS FILHO, 1998, p. 184).

Ademais, o autor é aquele que cria ou dá origem a uma obra literária, artística ou científica e pode ser conhecido pelo nome civil, nome fictício ou qualquer que o torne reconhecido por sua criação. Nessa lógica, também será o titular dos direitos autorais aquele que adapta, traduz, organiza ou orquestra uma obra de domínio público e não pode se opor a outra adaptação, orquestração ou tradução, a menos que seja cópia de sua autoria. Quem apenas ajudou o autor na produção da obra não é considerado coautor, uma vez que os coautores são considerados geradores do tema ou enredo literário-musical ou que criam os detalhes utilizados na obra.

"A proteção aos direitos autorais independe do registro, mas o autor pode registrar sua obra”. (MARTINS FILHO, 1998, p. 185). Sendo assim, os autores podem registrar seus trabalhos intelectuais em diversas instituições - Biblioteca Nacional, Escola de Música e de Belas-Artes da Universidade do Rio de Janeiro, entre outros - e validar legalmente sua autoria.

Os direitos morais e econômicos da obra intelectual pertencem ao autor, que a qualquer tempo reivindicará a autoria da criação quando utilizada por terceiros. Dessa maneira, o autor tem o direito de garantir a integridade de sua obra e se opor a qualquer modificação que possa prejudicar sua honra como autor. Além disso, também poderá modificar a obra, retirá-la de circulação ou suspender o uso já autorizado se a utilização implicar uma afronta à sua reputação.

RC: 88177

Disponível em: https://www.nucleodoconhecimento.com.br/arte/cadeia-produtiva 


\section{A TRANSIÇÃO DO MERCADO MUSICAL E OS IMPACTOS NA PRODUÇÃO}

Será que nos lembramos da última vez que paramos tudo para ouvir um disco que estava tocando no aparelho em nossa sala? Ou nos identificamos mais com a cena de tocar no celular e ouvir nossa música favorita nos fones de ouvido enquanto nos movemos de um lugar para outro? O fato é que mudamos os hábitos de consumo de cultura, seja música, livros ou filmes. Desta forma, a tecnologia pode até ter mudado as formas de produção, mas a legislação foi adaptada para garantir os direitos dos trabalhadores do setor cultural.

As tecnologias digitais têm transformado os hábitos de ouvir músicas. Há algum tempo atrás, carregar consigo músicas exigia-nos um grande esforço. Era necessário, se quisesse fazer um consumo musical independente de shows ou apresentações musicais - onde precisa da copresença - ter mídias físicas limitadas; o que tornava árdua a possibilidade de trocar conhecimentos musicais com outros indivíduos ou em outras situações, como se vê atualmente. (SANTOS; MACEDO; BRAGA, 2016, p.1).

Se hoje ouvimos música pela da internet, será que os autores e artistas que participaram do processo criativo daquela obra estão sendo pagos por isso? Em vista disso, a Lei 9.610, de 19 de fevereiro de 1998, aplica-se a todas as plataformas digitais e também garante os direitos autorais na era da rede de computadores.

Sabe-se que a sociedade vem passando por transformações significativas na forma de consumir música. Nossos pais ouviam músicas em discos e agora temos tudo na palma da nossa mão e podemos assistir e ouvir o que quisermos. No entanto, também tivemos profundas mudanças na forma de produção na era digital. Nakano (2010, p. 627) salienta que

Desde os anos 1950, a indústria fonográfica vem passando por transformações sucessivas, comandadas pelo desenvolvimento tecnológico. De um setor dominado por grandes empresas verticalizadas, com pequena diversidade de produtos, ela passou a ser uma indústria na qual pequenas e médias empresas desempenham papel importante na prospecção de tendências e lançamento de

RC: 88177

Disponível em: https://www.nucleodoconhecimento.com.br/arte/cadeia-produtiva 
produtos. Nela, as atividades de manufatura e distribuição são executadas por fornecedores especializados, e o mercado é compartilhado entre as grandes e as pequenas e médias empresas. A Cadeia de Produção Musical vem passando atualmente por uma fase de incertezas e indefinições, devido às novas possibilidades criadas pela chamada "desmaterialização da música", isto é, a distribuição de música pela internet ou pela telefonia celular.

Tudo parte do princípio de como a produção é feita. No passado, precisávamos de um grande estúdio de gravação e os meios de produção eram muito caros. Porém, o que vem acontecendo nos últimos anos é que esse acesso à tecnologia tornou as formas de produção muito baratas.

Então, há alguns anos, assistimos a um momento de produção e a oferta de conteúdo hoje disponíveis no mundo aumentou tremendamente, justamente porque o acesso que antes era muito proibitivo pelo custo tornou-se agora muito mais acessível para quem deseja entrar no mercado musical.

\section{FORMAS DE REMUNERAÇÃO}

À medida que se começa a produzir muito, passa-se a permear outras questões relacionadas a como divulgar e distribuir esse conteúdo. E são essas mudanças que, juntamente com as facilidades de acesso, vêm provocando as transformações na cadeia produtiva da música que vemos claramente acontecendo, e em meio a tudo isso está a remuneração dos criadores. Segundo Falcão; Soares Filho (2012, p. 54)

O autor da obra artística tem direito a receber contraprestação pecuniária pela utilização de sua obra por parte do usuário. Essa prerrogativa encontra guarida na Constituição Federal, a qual traçou as diretrizes básicas e indispensáveis à proteção de criações intelectuais garantindo, em seu artigo $5^{\circ}$, incisos XXVII e XXVIII, letra "b", que, em regra, somente o criador pode fixar o preço pela utilização de sua obra.

A grande questão na indústria musical de hoje é: como esses autores e artistas são pagos por seu trabalho? Isso vai depender de como a música é utilizada. Ainda existe a forma tradicional de uso - shows, concertos e apresentações ao vivo. Neste caso, os músicos são remunerados através do Escritório Central de Arrecadação de Direitos RC: 88177

Disponível em: https://www.nucleodoconhecimento.com.br/arte/cadeia-produtiva 
Autorais (ECAD)[3], o promotor do espetáculo paga uma taxa ao ECAD e o escritório distribui para todos os músicos.

Outra forma com que compositores, artistas e produtores fonográficos podem ser remunerados, é quando autorizam a sincronização dessa música em obras audiovisuais, ou seja, quando uma música entra em uma novela ou em um filme comercial. Assim, o produtor da obra audiovisual paga o direito de sincronização aos autores e produtores.

A internet ainda é a nova fronteira e há novos modelos de remuneração em teste, e hoje, basicamente, temos uma forma de remuneração atrelada à quantidade de visualizações - streaming - e ao número de acessos à música.

A palavra streaming é uma derivação de stream, que em inglês significa córrego ou riacho. Por isso que o termo remete para um fluxo de dados e conteúdos diversos como vídeos, músicas e jogos. É muito comum na internet assistirmos premiações e jogos em live streaming, permitindo que o usuário veja o que está sendo transmitido naquele momento. Para funcionar, o streaming de áudio e vídeo transfere suas informações por meio de um fluxo de dados de um servidor. Há também um decodificador que funciona como um tipo de navegador da web. O servidor, o fluxo de informações e o decodificador trabalham juntos para que o streaming aconteça. (SILVA JUNIOR, 2016, p.1).

Assim, se hoje assinarmos uma plataforma de streaming de música e pagarmos mensalmente por essa assinatura, podemos ouvir as músicas que quisermos. Portanto, essas plataformas fazem um cálculo interno que, a cada clique, os detentores dos direitos ganham uma determinada porcentagem do valor a partir da assinatura dos usuários. Por um lado, essa abundância de conteúdo é muito positiva porque dá ao usuário e ao amante da música acesso quase infinito à riqueza de música que temos. Porém, aumenta muito o número de compositores e autores que precisam compartilhar recursos ainda relativamente pequenos.

Se partirmos do pressuposto assinatura mais cara do Spotify — aproximadamente 35 reais que é o plano familiar e dá direito a 6 pessoas ouvirem várias músicas por mês

RC: 88177

Disponível em: https://www.nucleodoconhecimento.com.br/arte/cadeia-produtiva 
-, ao final, parte desses 35 reais ficará com o administrador da plataforma e a outra parte será distribuída para os músicos, compositores e produtores fonográficos.

Figura 1 - Planos Premium

\section{Escolha seu plano Premium}

Ouça sem limites no seu celular, alto-falante e em outros dispositivos.

$$
\text { visa } 1 \text { aㅡ }
$$

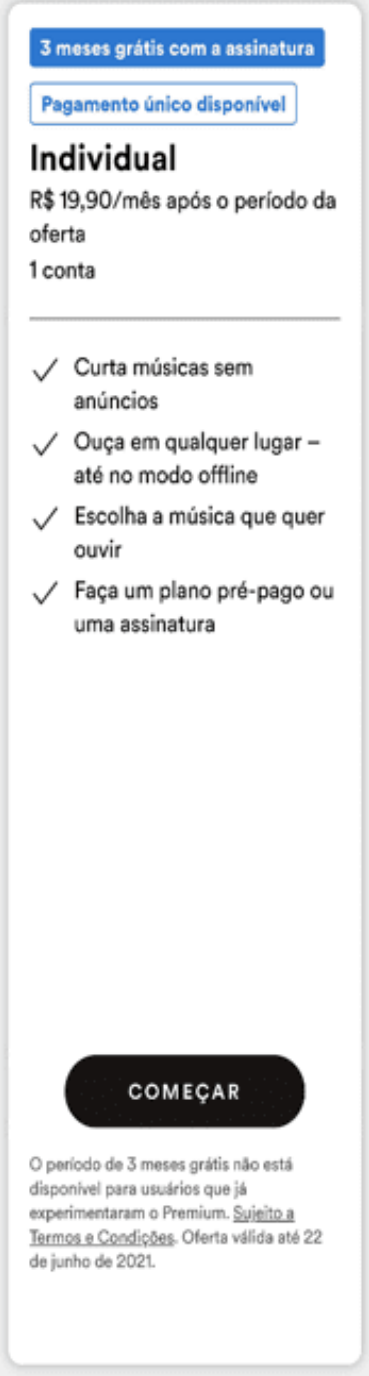

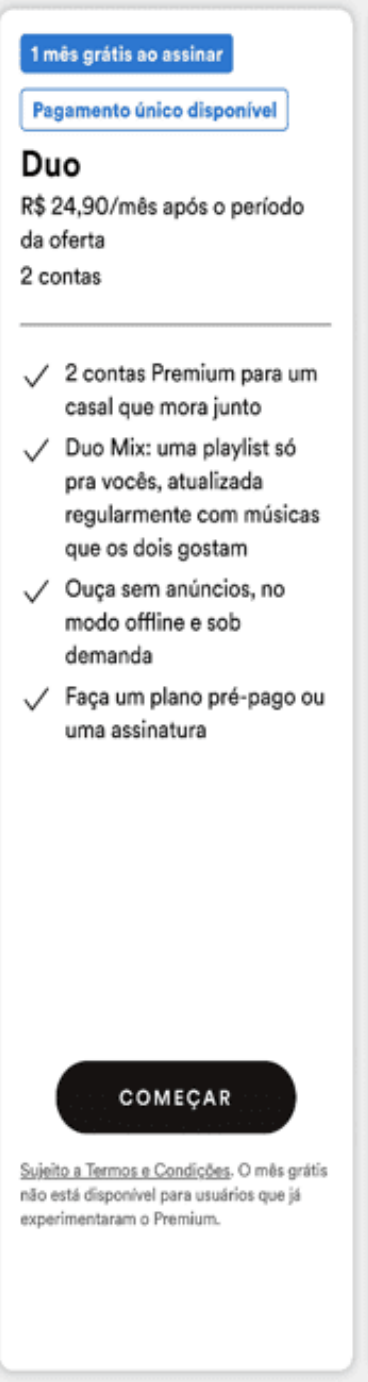

\section{1 môs grátis ao assinar \\ Pagamento único disponivel \\ Família \\ R\$ 34,90/mês após o período da oferta \\ Até 6 contas
$\checkmark 6$ contas Premium para familiares que moram no mesmo endereço \\ $\checkmark$ Mix para a Familia: uma playlist pra familia, atualizada regularmente com músicas que todo mundo gosta \\ $\checkmark$ Bloqueie músicas com conteúdo explicito \\ $\checkmark$ Ouça sem anúncios, no modo offline e sob demanda \\ $\checkmark$ Spotify Kids: um aplicativo separado, feito especialmente para crianças \\ $\checkmark$ Faça um plano pré-pago ou uma assinatura}

\section{COMEÇAR}

Suicito a Termose Condicless, O mbis gratis nảo está disponivel para usuărios que id experimentaram o Premium.

\section{1 mós grátis ao assinar}

\section{Universitário}

R\$ 9,90/mês após o período da oferta

1 conta

Desconto especial para estudantes universitários que tenham direito à oferta

$\checkmark$ Curta músicas sem anúncios

$\checkmark$ Ouça em qualquer lugar até no modo offline

$\checkmark$ Escolha a música que quer ouvir

Fonte: Spotify (BR) (2021).

RC: 88177

Disponível em: https://www.nucleodoconhecimento.com.br/arte/cadeia-produtiva 
Se ampliarmos essa questão, teremos o mercado de filmes e séries que funciona exatamente a partir do mesmo sistema de remuneração. Nessa lógica, o mercado procura se adaptar porque o valor não pode ser tão baixo ao ponto de inviabilizar a remuneração dos artistas ou tão alto que desestimule o consumidor dos meios legais. Portanto, o consumidor desestimulado a consumir legalmente acaba optando pela pirataria, e isso é o pior de tudo, porque se você não paga a ninguém, não paga imposto, o que gera prejuízo para o mercado.

\section{O DINÂMICA DO MERCADO MUSICAL}

A dinâmica do mercado é interessante porque no momento em que o NAPSTER[4] apareceu, era como se o novo mundo estivesse abrindo novos caminhos - tudo disponível a qualquer momento com o surgimento do MP3 - que tirou as rédeas e o muro que cercava o controle das grandes gravadoras.

Para Martins Filho (1998, p. 187) a "informática está provocando o surgimento de uma nova cultura, com novos conceitos de comercialização". Neste sentido, houve uma quebra total de paradigmas, onde as entidades que tinham maior controle, perderam completamente a gestão daqueles conteúdos que colocavam no mercado.

"Novas tecnologias midiáticas não cessam de emergir em um ritmo cada vez mais intenso até se tornar verdadeiramente avassalador a partir do advento do universo digital”. (SANTAELLA, 2015, p. 46). Por este ângulo, de um dia para o outro, o mercado se viu em uma situação em que de repente todos podiam ter acesso a tudo ao que queriam, mas não tinha controle e não tinha remuneração.

Por alguns anos parecia que o mercado da música havia entrado em colapso e aquele modelo que se perpetuou por muitos anos foi demolido. E realmente, de certa forma esse fenômeno acabou trazendo novos paradigmas para a indústria musical.

Com o avanço da tecnologia, naquele momento a legislação não conseguiu acompanhar o desenvolvimento tecnológico, porque não tinha como remunerar e

RC: 88177

Disponível em: https://www.nucleodoconhecimento.com.br/arte/cadeia-produtiva 
tampouco tinha um modelo de negócio desenhado. Pereira (2011, p. 119) afirma que, "a própria música popular se constituiu como um fenómeno à escala global, envolvendo processos cada vez mais dinâmicos e complexos de produção, distribuição, circulação e consumo". Com o passar dos anos, os hábitos de consumo e de comportamento foram se transformando e a tecnologia passou a ser baseada na forma como as pessoas a consomem e lidam com ela.

Inevitavelmente, antes mesmo de ter essa lógica do mercado musical atual, as empresas de tecnologia implantam um novo raciocínio. A própria Apple lançou um produto de hardware em 2001 - iPod - e decidiu que deveria haver uma maneira de as pessoas consumirem música legalmente. Naquela época, a loja iTunes foi lançada. Foi neste momento que se rompeu completamente o formato no qual a indústria musical havia trabalhado toda a sua vida — formato em suporte físico.

A indústria da música viveu por muito tempo de hits e até hoje funciona, mas o hit foi baseado em um álbum inteiro. $O$ disco inteiro foi comprado em função da aquisição de apenas um fonograma.

A partir do momento em que o iTunes lançou aquele novo modelo estabeleceu dois paradigmas totalmente inovadores - a venda por faixa e o preço único - porque a indústria sempre se baseou em discos de lançamento mais caros e discos de catálogo com preço mais antigo.

Naquele momento, houve um nivelamento de todos os álbuns, desde o novo lançamento do Metallica até aquele antigo álbum do Jorge Ben, todos com o mesmo preço. Portanto, foi uma ruptura completa de paradigma e um novo modelo de negócio e remuneração foi estabelecido. Desse modo, podemos dizer que a música é uma das principais responsáveis pela monetização dos conteúdos disponíveis na internet.

$\mathrm{RC}: 88177$

Disponível em: https://www.nucleodoconhecimento.com.br/arte/cadeia-produtiva 


\title{
LEGISLAÇÃO E OS AVANÇOS TECNOLÓGICOS
}

A lei de direitos autorais brasileira - Lei 9.610, de 19 de fevereiro de 1998 - é anterior à Internet e não tem sido capaz de acompanhar de perto essas mudanças tão significativas. Consequentemente, passou por alguns ajustes ao longo desse tempo, principalmente na área de gestão coletiva de música. No entanto, não podemos dizer que ela foi totalmente adaptada ao mundo da internet, o que não significa que não se aplique à rede.

Os conceitos básicos de direito autoral continuam aplicáveis à internet e ninguém pode usar a obra de um compositor sem sua autorização ou do titular, era assim antes da internet e continua sendo.

Essa autorização pode ser gratuita ou paga e a partir daí todos os trabalhadores culturais são remunerados. Isso inclui o compositor, o produtor musical, o arranjador e todos que trabalharam artisticamente na concepção daquela obra e na finalização daquele produto. Por este ponto de vista, surge a licença Creative Commons. Araya; Vidotti (2010, p. 97) ressaltam que,

\begin{abstract}
O Creative Commons é um projeto sem fins lucrativos, de adesão voluntária, sediado na Universidade Stanford, nos Estados Unidos. Ele é responsável por uma nova forma de direito autoral, pois disponibiliza um conjunto de licenças para áudio, imagem, vídeo, texto e educação que permite a autores e criadores de conteúdo intelectual, como músicos, cineastas, escritores, fotógrafos, blogueiros, jornalistas, cientistas, educadores e outros, indicar à sociedade, de maneira fácil, padronizada, com textos claros baseados na legislação vigente, sob que condições suas obras podem ser usadas, reusadas, remixadas ou compartilhadas legalmente.
\end{abstract}

Dessa maneira, existem uma série de contratos na produção em que os artistas cedem ou licenciam esses direitos mediante determinadas remunerações. No final das contas, a figura do titular que é o proprietário dos direitos patrimoniais sobre aquela música. Além disso, ainda é preciso da autorização do proprietário para usar a obra na internet. Sob esta ótica, não é porque o conteúdo é encontrado na internet que ele está livre de direitos autorais. O correto é, se você encontrou conteúdo na Internet, RC: 88177

Disponível em: https://www.nucleodoconhecimento.com.br/arte/cadeia-produtiva 
provavelmente esse site negociou esse conteúdo com o proprietário. Portanto, a legislação continua protegendo o autor, com apenas algumas alterações.

Não há como a legislação evoluir na mesma velocidade que a tecnologia, visto que a tecnologia está evoluindo muito rápido e a mudança na legislação é burocrática, pois requer discussão com a sociedade e aprovação do Congresso Nacional. Portanto, o Poder Judiciário muitas vezes desempenha esse papel e por meio de julgamentos no seu dia a dia, surgem jurisprudências - o entendimento e as decisões reiteradas pelo Judiciário - que muitas vezes são mais rápidas do que a própria legislação. Na hora de interpretar a lei, o judiciário tem cuidado da aplicação na internet.

Assim, podemos dizer que hoje para falar de direito autoral na internet, não basta olhar para legislação, é preciso olhar para legislação e jurisprudência porque a mudança da lei é muito lenta e a tecnologia é muito rápida.

\section{PRODUÇÃO MUSICAL NA INTERNET}

Existe uma questão que é importante quando falamos em produção musical, as gravadoras vêm se adaptando a esse novo formato da indústria, mas temos artistas autônomos que também têm a facilidade de produzir conteúdo caseiro e ter um canal no YouTube.

O YouTube é o principal destino musical do planeta, pois como o conteúdo lá está sob demanda, o usuário pode ver o que quiser e na hora que quiser. Na época em que essa tecnologia foi inventada, o YouTube foi questionado pelas próprias gravadoras que diziam que as pessoas costumavam usar conteúdo de terceiros que pertenciam a essas empresas. Em consequência disso, com o passar do tempo, surge o Content ID. Para YouTube (2018a)

O Content ID é uma ferramenta utilizada para identificar [...] e gerenciar o conteúdo no YouTube com facilidade. O Contend ID é um algoritmo que busca e identifica correspondências nos vídeos que são upados para o YouTube e os materiais protegidos por direito autoral. $\mathrm{Na}$ prática, ele verifica todo vídeo que é enviado, comparando-o com

RC: 88177

Disponível em: https://www.nucleodoconhecimento.com.br/arte/cadeia-produtiva 
"banco de dados", ou de "referências", que é formado por arquivos enviados pelos próprios proprietários do conteúdo. Quando uma correspondência for encontrada o vídeo recebe uma reivindicação do Content ID (apud AMARAL; BOFF, 2018, p. 50).

Sendo assim, o YouTube criou um modelo de negócio que é fundamental na indústria, que hoje cria um sistema que basicamente permite que o fonograma seja detectado pelo sistema toda vez que a gravadora dona do conteúdo o insere no sistema da plataforma.

Este sistema cria uma camada informando a qual empresa aquela música pertence. Assim, em relação a outras pessoas jurídicas ou pessoas físicas que utilizem música de terceiros, o sistema no YouTube detecta e remunera de forma a criar um modelo de negócio que hoje seja sustentável e muitas empresas e muitos artistas não vivem apenas da música, como vivem de criar seus próprios canais.

Isso funciona tanto para artistas que criaram seu próprio canal usando-o como uma ferramenta de disseminação e propagação, quanto para músicas que são usadas em canais pessoais em vídeos de esportes, festas de aniversário, etc. Qualquer música usada no sistema do YouTube permite que o proprietário do conteúdo seja pago, o que, portanto, criou um novo modelo de negócios que não existia até recentemente.

Em relação a todas essas questões, o Brasil, por ser grande, é considerado um dos três maiores países de engajamento social no YouTube e está entre os dez maiores países de monetização do mundo. Isso traz, por parte dos provedores de conteúdo, uma atenção maior quando se trata de ver o conteúdo que eles sabem gerar audiência. Por isso, hoje a concorrência viu que as pessoas querem ter a atenção do usuário final em casa. Dessa forma, surge uma nova profissão - YouTuber - que gerou as celebridades que todo mundo conhece de uma audiência que nasceu em casa, e o mesmo aconteceu com os artistas.

Uma característica marcante desse produtor de conteúdo audiovisual no YouTube, o YouTuber, é a capacidade de produção de conteúdo com equipes reduzidas e da relação que administra com o público consumidor. Diferente da relação anterior de mídias tradicionais como

$\mathrm{RC}: 88177$

Disponível em: https://www.nucleodoconhecimento.com.br/arte/cadeia-produtiva 
cinema e televisão, não há o respaldo de grandes empresas para construção de uma celebridade. O cenário atual apresenta um produtor de conteúdo que deve construir seu alcance e sua capacidade de "influenciador" a partir da relação que desenvolve com outros produtores, com marcas e com o público. (LEITE, 2019, p. 44).

Muitos artistas que conhecemos hoje foram acionados por grandes gravadoras porque, no passado, era muito caro se promover e desenvolver sua carreira. Um exemplo disso é Justin Bieber, que como muitos outros artistas emergiu da audiência que ele mesmo criou.

Existem rádios que hoje pegam covers que tocam no YouTube e colocam em suas playlists. Desse modo, muitas músicas que surgiram espontaneamente e que muitas vezes nem chegam ao meio tradicional — rádio e televisão - viralizaram a partir da rede social, e o mais importante, é que estão sendo monetizadas e remunerando o proprietário do conteúdo.

Nossa legislação está falhando em monitorar, promover ou buscar essas mudanças. Portanto, esses avanços e toda essa nova forma de remuneração, proibição ou uso de conteúdo online, na verdade, são movimentos isolados de atualização.

Um exemplo disso é que o Ministério da Cultura lançou uma Instrução Normativa[5] sobre gestão coletiva de direitos autorais no ambiente digital que trata de como artistas, autores e titulares de direitos podem aderir a associações de gestão coletiva para rentabilizar, receber e distribuir os recursos advindos da internet.

\section{CONSIDERAÇÕES FINAIS}

Na prática, este mundo é tão novo, mudou tão rápido, que um rearranjo institucional e legislativo e uma repactuação entre os diferentes atores do mercado é realmente necessário para que todos entendam que, na realidade, não existem velha e nova mídia, os meios de comunicação são sempre os mesmos e hoje todos estão no mundo digital.

$\mathrm{RC}: 88177$

Disponível em: https://www.nucleodoconhecimento.com.br/arte/cadeia-produtiva 
O que existe são criadores, produtores e distribuidores de conteúdo. Portanto, se o criador e o produtor não forem pagos, nenhum terceiro precisa distribuir. Todos estão cientes disso, inclusive os atores desta história que relutam em pagar direitos autorais e que por um tempo pensaram que não era necessário porque este modelo estava morto. Mas mesmo estes atores, já perceberam que sem um conteúdo que faça sentido, os mais modernos iPad, iPod ou qualquer outra tecnologia são apenas bugigangas. Sob esse ângulo, as pessoas ouvem música e assistem filmes e, no final das contas, o importante é o conteúdo.

$\mathrm{Na}$ verdade, a música nunca teve tanto peso, pois no encerramento da cerimônia das Olimpíadas, vimos que a música norteou o evento em sua totalidade, passeando por todas as culturas brasileiras.

O fato é que dessas principais fontes de receita do artista e do autor — execução pública, sincronização e direito de reprodução - , o que mudou é que há algum tempo não havia streaming, porque a banda larga ainda não era suficiente e o modelo de negócio não era aprovado.

O modelo de download era semelhante ao do disco — baixou, vendeu por um, e pagase x. Quando o modelo de streaming surge, há dúvidas sobre qual direito você realmente tem de pagar.

À medida que determinado conteúdo é transmitido, algumas vertentes acreditam que esse direito faz parte do modelo de execução pública e outras pessoas acham que não, porque é um direito privado, pois estou pagando e escolhendo. A discussão que está em pauta no Brasil é justamente quanto dessa remuneração deve ou não ser colocada em execução pública.

Essa é uma discussão que não chegou a uma conclusão muito rápida, mas provavelmente o Brasil vai liderar esse processo em termos globais, pois somos um país altamente significativo em termos de volume.

RC: 88177

Disponível em: https://www.nucleodoconhecimento.com.br/arte/cadeia-produtiva 
As empresas que hoje atuam no mercado digital estão de certa forma entusiasmadas com o Brasil, pois temos uma população onde muito se produz e muito se consome. Consequentemente, temos uma camada de telefones celulares e assinantes muito maior do que a de habitantes.

Isso traz uma relevância incrível para o mercado. Portanto, temos que agilizar os modos de operação para que a cadeia produtiva seja oficialmente estabelecida.

\section{REFERÊNCIAS}

AMARAL, Jordana Siteneski do; BOFF, Salete Oro. A Falibilidade do Algoritmo Content ID na identificação de violações de Direito Autoral nos Vlogs do YouTube: Embates sobre Liberdade de expressão na Cultura Participativa. Revista de Direito, Inovação, Propriedade Intelectual e Concorrência, Porto Alegre, v. 4, p. 43-62, Jul/Dez. 2018. Disponível em: https://bit.ly/3fofLyz. Acesso em:27 mai. 2021.

ARAYA, Elizabeth Roxana Mass; VIDOTTI, Silvana Aparecida Bursetti Gregório. Criação, proteção e uso legal de informação em ambientes da World Wide Web. São Paulo: Editora UNESP, 2010. Disponível em: https://bit.ly/3wDWyz0. Acesso em: 27 mai. 2021.

BRASIL. Instrução Normativa $\mathbf{n}^{\circ} \mathbf{2}$, de $\mathbf{4}$ de maio de 2016. Estabelece procedimentos complementares para a habilitação para a atividade de cobrança, por associações de gestão coletiva de direitos de autor e direitos conexos, na internet, conforme definida no inciso I do caput do art. $5^{\circ}$ da Lei $n^{\circ} 12.965$, de 23 de abril de 2014. Disponível em: https://bit.ly/3wvs02a. Acesso em: 24 mai. 2021.

Lei 5.988, de 14 de dezembro de 1973. Regula os direitos autorais e dá outras providências. Brasília: Casa Civil, [1973]. Disponível em: https://bit.ly/33SbLzU. Acesso em: 16 abr. 2021.

RC: 88177

Disponível em: https://www.nucleodoconhecimento.com.br/arte/cadeia-produtiva 
Lei $\mathrm{n}^{\circ}$ 9.610, de 19 de fevereiro de 1998. Altera, atualiza e consolida a legislação sobre direitos autorais e dá outras providências. Brasília: Casa Civil, [1998]. Disponível em: https://bit.ly/3yh5YSF. Acesso em: 16 abr. 2021.

FALCÃO, Caio Valério Gondim Reginaldo; SOARES FILHO, Sidney. Direito autoral e ecad: análise jurisprudencial do papel do escritório central de arrecadação e distribuição na cobrança judicial pela execução pública de obras musicais e congenêres. Revista Jurídica da FA7, Fortaleza, v. 9, p. 53-64, 30 abr. 2012. Disponível em: https://bit.ly/3whHd72. Acesso em: 24 abr. 2021.

LEITE, Rafaela Bernardazzi Torrens. Youtuber: o produtor de conteúdo do Youtube e suas práticas de produção audiovisual. 2019. Tese (Doutorado em Estudos da Mídia e Práticas Sociais) - Centro de Ciências Humanas, Letras e Artes, Universidade Federal do Ro Grande do Norte, Natal, 2019. Disponível em: https://bit.ly/3wsg5SA. Acesso em: 24 mai. 2021.

LIMA, Mauricio Marley Saraiva. A evolução do mercado musical: da" pirataria" às novas mídias digitais. 2013. Monografia (Graduação em Ciências Econômicas) Faculdade de Economia, Administração, Atuária, Contabilidade e Secretariado, Universidade Federal do Ceará, Fortaleza, 2013. Disponível em: https://bit.ly/3tXxctZ. Acesso em: 03 mai. 2021.

MARTINS FILHO, Plínio. Direitos autorais na Internet. Ciência da Informação, v. 27, n. 2, p. nd-nd, 1998. Disponível em: https://bit.ly/3whEeeA. Acesso em: 28 abr. 2021.

NAKANO, Davi. A produção independente e a desverticalização da cadeia produtiva da música. Gestão \& Produção, v. 17, n. 3, p. 627-638, 25 out. 2010. Disponível em: https://bit.ly/3bB2TD7. Acesso em: 09 mai. 2021.

PEREIRA, Sónia. Estudos culturais de música popular: uma breve genealogia. Exedra, Coimbra, v. 5, p. 117-133, 2011. Disponível em: https://bit.ly/3umeOv9. Acesso em: 25 mai. 2021.

RC: 88177

Disponível em: https://www.nucleodoconhecimento.com.br/arte/cadeia-produtiva 
SANTAELLA, Lucia. A grande aceleração \& o campo comunicacional. Intertexto, Porto Alegre, n. 34, p. 46-59, set./dez. 2015. Disponível em: https://bit.ly/3fNN3pS. Acesso em: 25 mai. 2021.

SANTOS, Bluesvi; MACEDO, Wendell; BRAGA, Vitor. O streaming de música como um estímulo para a ampliação do consumo musical: um estudo do Spotify. In: CONGRESSO BRASILEIRO DE CIÊNCIAS DA COMUNICAÇÃO, 29., 2016, São Paulo. Anais [...]. São Paulo: Intercom - Sociedade Brasileira de Estudos Interdisciplinares da Comunicação, 2016. Disponível em: https://bit.ly/341MFhX. Acesso em: 20 abr. 2021.

SILVA JÚNIOR, Flávio Marcílio Maia e. Na Onda do Streaming: Plataformas Digitais Sonoras no Mercado Musical Brasileiro. In: CONGRESSO DE CIÊNCIAS DA COMUNICAÇÃO NA REGIÃO NORDESTE, 18., 2016, Caruaru. Anais [...]. Caruaru: Intercom - Sociedade Brasileira de Estudos Interdisciplinares da Comunicação, 2016. Disponível em: https://bit.ly/3bYldVT. Acesso em: 26 mai. 2021.

SPOTIFY Premium. Spotify (BR), Premium, 27 mai. 2021. Disponível em: https://spoti.fi/2QYkPk1. Acesso em: 26 mai. 2021.

\section{APÊNDICE - REFERÊNCIA DE NOTA DE RODAPÉ}

3. Atualmente, o ECAD é administrado por dez associações de músicas, com sede na cidade do Rio de Janeiro, tendo 25 unidades arrecadadoras, 700 funcionários, 60 advogados prestadores de serviços e 131 agências autônomas instaladas em todos os Estados da Federação. (FALCÃO; SOARES FILHO, 2012, p. 56).

4. O NAPSTER foi um programa desenvolvido com o intuito de compartilhar arquivos em rede "peer-to-peer" (P2P) onde o usuário poderia fazer downloads de músicas, vídeos, programas, jogos de forma totalmente gratuita. (LIMA, 2013, p. 16).

RC: 88177

Disponível em: https://www.nucleodoconhecimento.com.br/arte/cadeia-produtiva 
5. INSTRUÇÃO NORMATIVA MINC № 2, DE 4 DE MAIO DE 2016: Estabelece procedimentos complementares para a habilitação para a atividade de cobrança, por associações de gestão coletiva de direitos de autor e direitos conexos, na internet, conforme definida no inciso I do caput do art. $5^{\circ}$ da Lei $n^{0} 12.965$, de 23 de abril de 2014. (BRASIL, 2016).

Enviado: Maio, 2021.

Aprovado: Junho, 2021. 